\title{
Service Systems and Value Modeling from an Appreciative System Perspective
}

\author{
Gil Regev $^{1,2}$, Olivier Hayard ${ }^{2}$, Alain Wegmann ${ }^{1}$ \\ ${ }^{1}$ Ecole Polytechnique Fédérale de Lausanne (EPFL), School of Com- \\ puter and Communication Sciences, CH-1015 Lausanne, Switzerland, \\ \{gil.regev, alain.wegmann\} @epfl.ch \\ ${ }^{2}$ Itecor, Av. Paul Cérésole 24, cp 568, CH-1800 Vevey 1, Switzerland \\ $\{\mathrm{g}$. regev, o.hayard\}@itecor.com
}

\begin{abstract}
Since its inception Service Science has created a substantial body of knowledge about services and their provision. Most notably, the concept of Service System was defined in order to describe the co-creation of value by the service provider and customer. We introduce the concept of Appreciative System defined by Vickers in the study of the way individuals and organizations apprehend and act on their environment. We show how the appreciative system concept can be applied to a service system model with the SEAM enterprise architecture method.
\end{abstract}

\section{Introduction}

The concept of Service System was defined in Service Science in order to describe the co-creation of value by the service provider and customer [8]. The definition of service as a system results in much attention given to Systems Thinking in recent Service Science publications [8, 14]. It has been proposed that the concept of service is linked to system survival. Most research in this direction has thus far used Beer's Viable Systems Model to analyze properties of Service Systems [2]. The substantial research into Service Systems has raised as many questions as answers about value co-creation [14].

In this paper we propose to analyze service systems and value cocreation from the perspective of Vickers's appreciative system. We begin from the roots of Systems Thinking to explore the notions of system and system survival based on the works of Weinberg and Weinberg $[21,22]$. We then analyze the valuation process with Vickers's Appreciative System $[15,16]$. We then show how these concepts can be used for the practical modeling of service systems using the Systemic Enterprise Architecture Method (SEAM) [18. 19]. We use the running example of Apple's iPod to illustrate the theory and the method. 
In Section 2 we first survey the state of the art of the research in Service Science concerning service systems and value. In Section 3 we introduce the fundamental aspects of systems and survival. In Section 4 we explain Vickers's appreciative system. In Section 5 we illustrate these concepts with SEAM models and the iPod example. In Section 6 we compare our work with related research before outlining future research directions in Section 7.

\section{Service Systems and Value Creation in Service Science}

The following basic concepts of Service Science are defined in [14] as:

- Service is "the application of competences (knowledge and skills) by one entity for the benefit of another."

- Service Systems are interactive configurations of mutual exchange in which value is created collaboratively.

- Value is "an improvement in system well-being" and is measured in terms of "system's adaptiveness or ability to fit in its environment."

Further [14] state that "A service system's function is to make use of its own resources and the resources of others to improve its circumstance and that of others."

Service Science takes the view that marketing thought has to evolve from the Goods-Dominant (G-D) logic to a Service-Dominant (S-D) logic [14], G-D logic, according to [14], is based on the exchange of goods from supplier to consumer. In G-D logic, a supplier organization transfers or sells a product to a consumer. The value derived from this product by the customer depends on the customer's ability to use the product, resell it or transfer it to others. This is called value in exchange.

Conversely, S-D logic, also according to [14], is based not on the independent creation of value following the transfer of goods but on the co-creation of value jointly by the service supplier and the service customer. This is called value in use. The Co-creation of value refers to the need of the provider to be available for as long as the consumer uses the service. Contrast this with the G-D logic in which a product is sold to a customer (i.e. transferred to a customer for a fee). Thereafter, the 
product provider is not involved anymore in the value created by the customer because the product is not in its jurisdiction anymore.

S-D logic describes value in use as emerging from the cooperation between supplier and consumer within a Service System [2, 14]. A Service System is said to create value when interacting with other service systems [14].

The transition toward S-D logic shifts the focus of attention from value in exchange to value in use. Value in exchange, however, has not completely disappeared. Hence, for [14] "Co-creation of value inherently requires participation of more than one service system, and it is through integration and application of resources made available through exchange that value is created. The process of co-creating value is driven by value-in-use, but mediated and monitored by value-in exchange. The concepts of mediation and monitoring are not further specified.

Value creation has been linked to both the survival of the organization and to the disappearance of distinction between producer and consumer. [14] states that, "...at its core, value depends on the capabilities a system has to survive and accomplish other goals in its environment." and "When value creation is seen from a service systems perspective, the producer-consumer distinction disappears and all participants contribute to the creation of value for themselves and for others." Erasing the distinction between systems amounts to denying their survival. It is therefore unclear from these statements how a system survives and at the same time erases its distinction between itself and its producers and/or its consumers.

The discussion above shows that:

- Value in use and value in exchange interact in complex ways that are not yet fully understood. It is not clear what it means for value in use to be monitored and mediated by value in exchange.

- Erasing the distinction between producer and consumer may lead to denying their existence and hence their potentially differing points of view

- It is not clear how value creation influences survival.

In the following sections we formulate some answers to these points by linking the aspects of systems survival and valuation. 


\section{Systems and Survival}

We base our discussion of systems and survival from the point of view of General Systems Thinking, the study of general principles that can be applied to all systems [21,22].

Reflecting on system survival brings the obvious question of what is a system and what determines its survival. In its most general form, a system is defined as a set of interrelated elements as viewed by an observer $[11,12,13,21]$. The system exists, or survives, for a given observer for as long as the observer can identify it. The system therefore must maintain some unchanged states that the observer uses to identify it as different from any other system. The observer also must maintain a memory of these aspects of the system so that he or she can identify it. The observer has some limits on the variability of the aspects he or she sees in a system. We use the term norm to denote these stable, unchanging, states of both system and observer. For Apple, this means that once they launch a product named iPod, they must be very careful with any changes made to it. When some changes are made to the iPod product line, the new devices must be labeled accordingly so that customers may understand their differences as well as their relation to older versions. Hence, when new versions of the iPod are introduced they are called iPod Classic (the one that keeps the small screen and the wheel user interface) and the more innovative are called iPod Touch.

The elements and relationships that the observer considers as being part of the system fix the boundary of the system. Everything else is considered to be outside the system and is called the environment of the system. In the iPod example, considering only the iPod device with components such as screen, hard disk, and control software (and their relationships) fixes a boundary that corresponds to the iPod's value in exchange. If we add to it the iTunes service, we have a boundary that corresponds to the value in use.

The second law of thermodynamics states that a closed system will evolve towards disorder. That is, it will not be able to maintain its components and their relationships (its norms) in stable enough states for the observer to identify the system. Disorder is measured in terms of entropy. Higher entropy means more disorder. Lower entropy means less disorder, i.e. more order. The system therefore has to have relationships with other systems to exchange energy and information with them 
thereby maintaining the system's negative entropy (internal order, also called negentropy).

While these relationships are necessary, they are also potentially dangerous. For example, Apple needs the relationships with its suppliers in order to manufacture an iPod, but a supplier may supply components of insufficient quality, thereby threating the overall quality of the iPod. Apple must have mechanisms in place to control its relationships, including its suppliers and customers. The way a system manages its relationships is therefore of paramount importance to its survival. In the following section we describe Vickers's ideas about the way individuals and organizations manage their relationships, his concept of appreciative system

\section{Appreciative Systems and the Valuation Process}

Vickers specialized General Systems Thinking to the study organizational and individual valuation. Noting that most research in psychology and communication scienses alike has been targeted to the study of human action rather than to the study of the stages that predate action, Vickers proposed the concept of the Appreciative System, to model the way in which humans and organizations understand and act on their environment.

Vickers [15] calls metabolic relations the relationships that bind the elements of the system (its internal relationships). He calls functional or service relations the relationships with the environment (external relationships). Metabolic and service relations are interdependent one feeds the other. At Apple, for example, the selling of iPods (a service relation) is dependent on engineering, manufacturing and marketing (metabolic relations). Both metabolic and service relations need to be maintained in very specific states over time for the system to maintain its identity for a given observer.

The activity that maintains a relation in a specific state is called regulation. One of the simple regulation mechanisms is the automatic control mechanism, or feedback mechanism. An automatic pilot, for example, has to maintain an airplane in specific relations to its spatial environment in order to steer it to destination. Such an automatic pilot has a cyclical regulative process that can be separated into three stages [15]:

1. "information is received from the compass; 
2. it is compared with the course to be steered;

3. action or inaction is selected in response to a signal generated by the comparison."

Based on this simple regulation, Vickers proposes a model of human and organizational behavior, called the Appreciative System. Vickers' Appreciative System has three elements: Reality Judgment, Value Judgment and Action Judgment.

\section{Reality judgment}

Reality Judgment defines what a person or organization is ready to notice in themselves and in their environment. They form what the person or organization will be interested in, [15], "We notice only those aspects of reality which 'interest' us; we have language to describe only those aspects which interest us. Interest is the basic fact of mental life and the most elementary act of valuation."

\section{Value judgment}

Value judgment defines how what is noticed will affect present and future relations. This judgment is made on both service and metabolic relations. Value judgments are therefore closely linked to the survival of the individual or organization making the judgment. Remember that survival is the maintenance of an identity for a given observer. Hence altering the relationships with an observer can affect the survival of the individual or organization for that observer.

Vickers specifies that value judgment consists of a three-step process [15]:

- Matching: attaching a noticed phenomenon to an existing category.

○ Weighing: Evaluating the result of the matching step on present and future relations.

- Innovating: Creating a new category thereby enabling new phenomena to be observed and valued. 


\section{Action judgment}

Action judgment defines what behavior is appropriate to what has been noticed and the way it was valued. Vickers notes that visible action doesn't necessarily follow from the valuation. It is very possible that the valuation will be followed by a change of what to notice and how to value, in essence changing what is desired.

\section{Judgments and Readinesses}

The essential difference between an automatic pilot and an appreciative system is that for the former the norms (the course, the measurement of the direction and the comparison) are given at construction, whereas for the latter the norms evolve from within through experience.

For Vickers [15] each of these stages creates over time a readiness that defines what the system expects. Reality judgment creates a readiness to see. Value judgment creates a readiness to value. Action judgment creates a readiness to act. Or in Vickers's own words [15], an appreciative system is characterized by "the kinds of information it is ready to notice, the kinds of valuation it is ready to make, and the kinds of action it is ready to take."

Each of these readinesses can be studied as a system in its own right but they are interdependent in their functioning as a complete appreciative system [15], "The elaboration of the reality system and the value system proceed together. Facts are relevant only to some standard of value; values are applicable only to some configuration of facts."

These standards of value and configuration of facts can be studied as norms that the appreciative system (and its subsystems of reality, value and action) adheres to. The appreciative system constantly attempts to maintain these norms in a consistent state, resisting change that threatens the stability of each one of the its sub-systems and of the whole system. The adherence to norms, by definition, insures the stability of the system. But it also hampers creativity [12]. This process sets limits on the amount of change that an appreciative system can accept [16]. Hence, these norms are not impossible but are simply difficult to change.

Each appreciative system builds its own readinesses (its own norms) by which it apprehends the world, judges it and acts on it. In a service system what brings together a service supplier and a customer, as de- 
scribed in Section 2, each will have a different appreciative system. They may agree to see and value some aspects in the same way but because of their different interests, may very well disagree on many other aspects. The appreciative system concept tells us that it is very likely that one party may not even notice aspects that are valued as very important by the other party. What one party considers as improvement may be judged by another party as a deterioration, see for example [3]. The very "function" of a service is likely to be a subject to debate among its stakeholders, see [21]. In the next section we show how these differing views can be modeled with SEAM

\section{Modeling Service Systems and Value with SEAM}

Having explained the Appreciative System concept, we show how it can be modeled with SEAM. We use the example of Apple's iPod's valuation by a teenager called Kate. We first model the valuation leading to the purchase of an iPod by Kate, i.e. the value in exchange of an iPod. We then model the valuation of the service offered by Apple to Kate, i.e. the value in use of the iPod.

Within a service system we usually identify several interrelated systems, e.g., a service provider, a customer, competitor and regulator. For reasons of space, we limit our example to the interactions between the service provider and the customer.

The models we present in Figures 1 to 4 are extensions of the models presented in [19].

\section{The iPod's value in exchange}

When Apple launched the iPod in 2001 [10], it entered a market where many players existed already. Apple was by far not the first to offer an MP3 player. It therefore didn't enjoy the first mover advantage. Instead it was able to capitalize on norms that already existed and that have formatted customers' appreciative systems. MP3 players have existed for several years and consumers have come to understand their potential. Price ranges differentiated between low-end and high-end players.

Customers began by appreciating the iPod purely for its value in exchange, e.g. its design, price and performance. 
Establishing the iPod as a reference in the market was made possible by offering several features that set it apart from its competitors, such as a large screen, playlists, a good user interface, but these are not by themselves sufficient in explaining why Kate and her friends flocked to the iPod. Preceding the iPod, Apple created the iMac, which set a norm in PC design. This no doubt has helped Apple to launch the iPod and to make into its own standard. It also set the norm in the market that Apple was a manufacturer of very desirable computer devices, setting the stage for the successful introduction of the iPod.

The SEAM Systemic Value Network model in Figure 1 shows the market segment of the iPod Classic with Apple's Value Network providing an iPod Classic product to an adopter called Kate. The top left box within the iPod segment represents the Apple value network as a whole (designated by a [w]). Only the externally visible features of the iPod are shown. These features are, a 2.5" screen, a sleek design, the Apple brand, usability and 120 GB memory.

The bottom left box shows Apple's value network as a composite (designated by a [c]). This exposes the participants in the Apple value network. These are: Innolux who supplies the screen, Apple who supplies the software and industrial design, Toshiba who supplies the hard disk and Foxconn who assembles and packages the iPod. If so many of Kate's friends have iPods it means that Apple also maintains a set of norms that allow it to literally flood the market with iPods. We model this capability with the High sales volume feature in the model as a whole. All of Apple's suppliers will have to uphold this norm as well. We model this norm with the High production volume feature assigned to each supplier.

The top right box represents Kate who wants to buy an MP3 player. Kate has links with a network of friends who influence her appreciative system, and in effect create the reality judgment that Kate uses to make her choice of MP3 player. In this case, most of her friends have an iPod or would like to have one, which sets the readiness to notice mostly iPods even to the exclusion of any other MP3 when purchasing time comes. Kate sees the following value in an iPod, it is the same player as her friends, it is easy to select songs with it, she can have all her music on the go and the iPod is a cool device. 


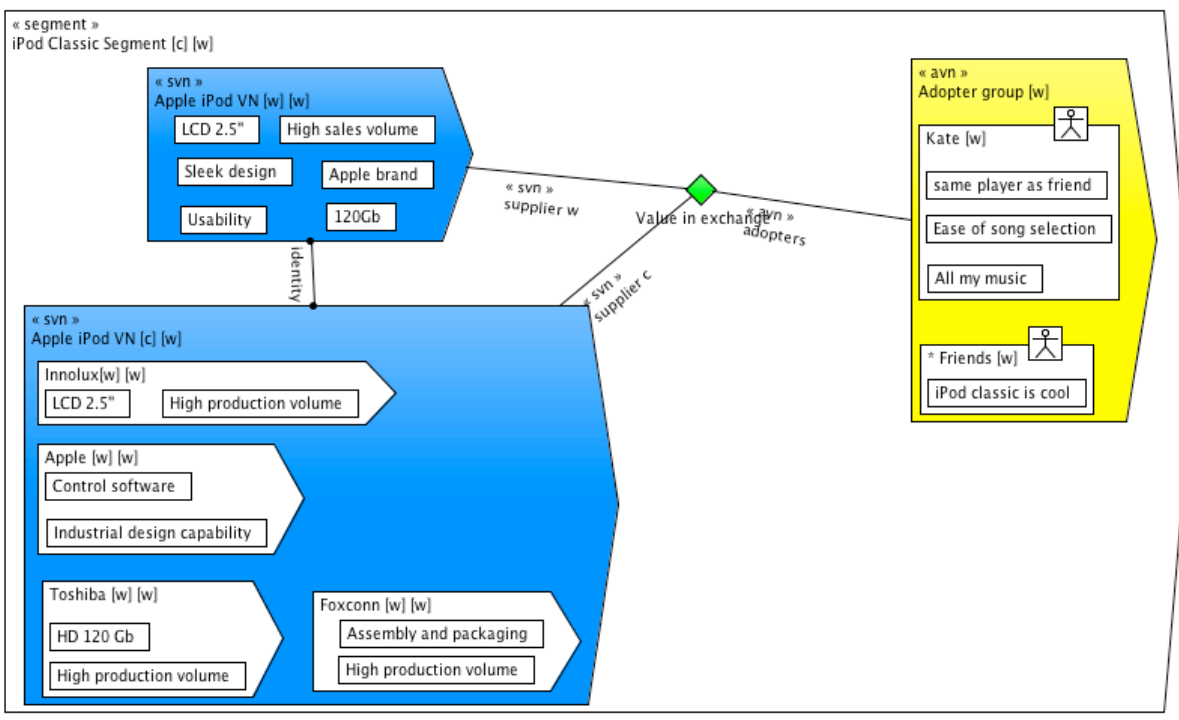

Figure 1 Service system model for value in exchange

iPod Classic Value in Exchange Model

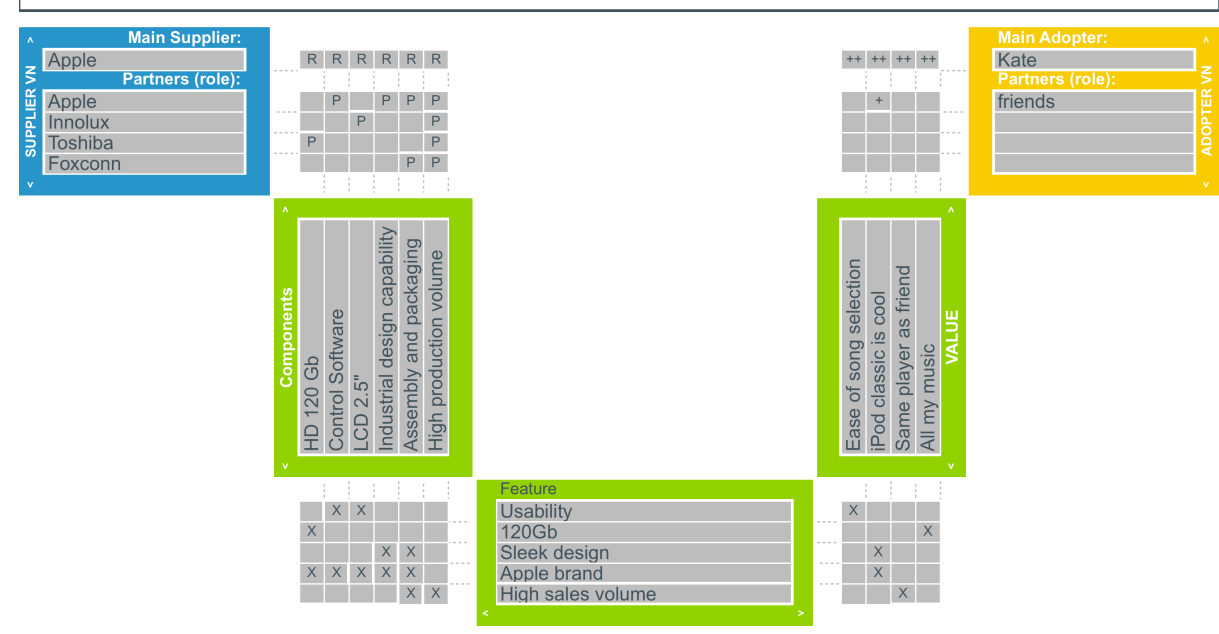

Figure 2 Value model for value in exchange

Figure 2, shows the value model corresponding to the service system model. From left to right we show a supplier value network creates components that exhibit features that are valued by a network of customers. The left side of the model corresponds to Apple's value network with its set of suppliers. We represent the suppliers in the hori- 
zontal list on the extreme left of the model and the component of the iPod in the vertical list on the left of the model. We match which supplier delivers which component with the responsibility matrix that links both lists.

The middle and right side of the model correspond to Kate's appreciative system. The,+++ (and potentially - and --) signs correspond to the weighing step in the value system as described in Section 3. The value itself (e.g. iPod classis is cool) corresponds to the matching step of the value system. In the middle of the model we represent the features of the iPod that the Apple value network creates and that Kate notices through her reality system. The features of the iPod are common to both the Apple value network and Kate's reality system. Kate's reality and value systems together form Kate's appreciative system. We can see that Kate's network of friends gives much value to the coolness of the iPod. Kate places much value on having the same MP3 player as her friends in order to maintain her relationships with them. This means maintaining her membership in her peer group, i.e. surviving in that group. This explains Kate's choice of the iPod. Notice that this valuation is aligned with Vickers's description of the value system, which consists of judging how what is noticed will affect present and future relationships.

\section{The iPod's value in use}

Figures 3 and 4 show the model of the iPod value in use. It corresponds to a different value network for Apple and a different appreciative system for Kate. The ubiquity of iPods in the market (due to their value in exchange) enables Apple to provide a service centered around the iPod, and therefore dependent on its value in exchange. The iTunes store proposes a service with which iPod users can buy music from the iPod or from the web. Apple's value network for the value in use is made of Sony Music Entertainment, Apple's iTunes, Warner Music Group and Independent musicians, each providing part of the service.

For a teenager such as Kate with a limited budget, the value in use represented by iTunes is not all positive. The relatively high prices of individual songs and albums compared to budget CDs available in stores is a big strain on her budget. The effect of copy protection on the possibility to copy songs is also a problem. The high price of songs and the difficulty to copy songs are therefore modeled as negative values by 
Kate and her friends. Kate, however, values positively the free songs offered weekly on iTunes.

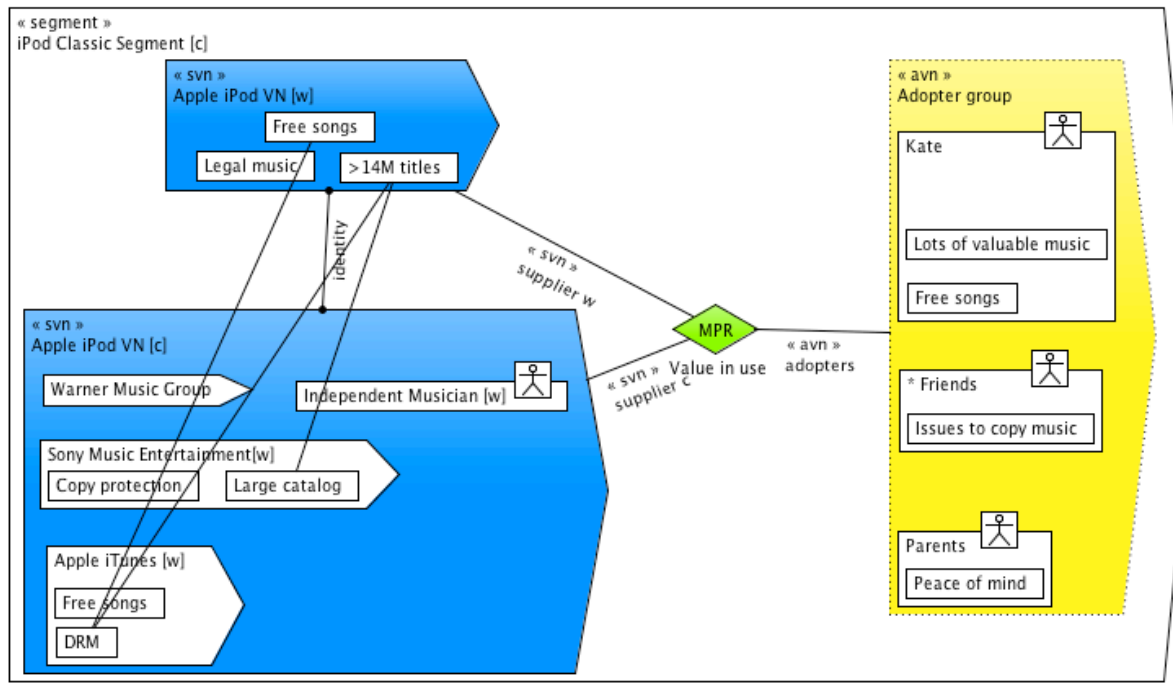

Figure 3 Service system model for value in use

iPod Classic Value in Use Model

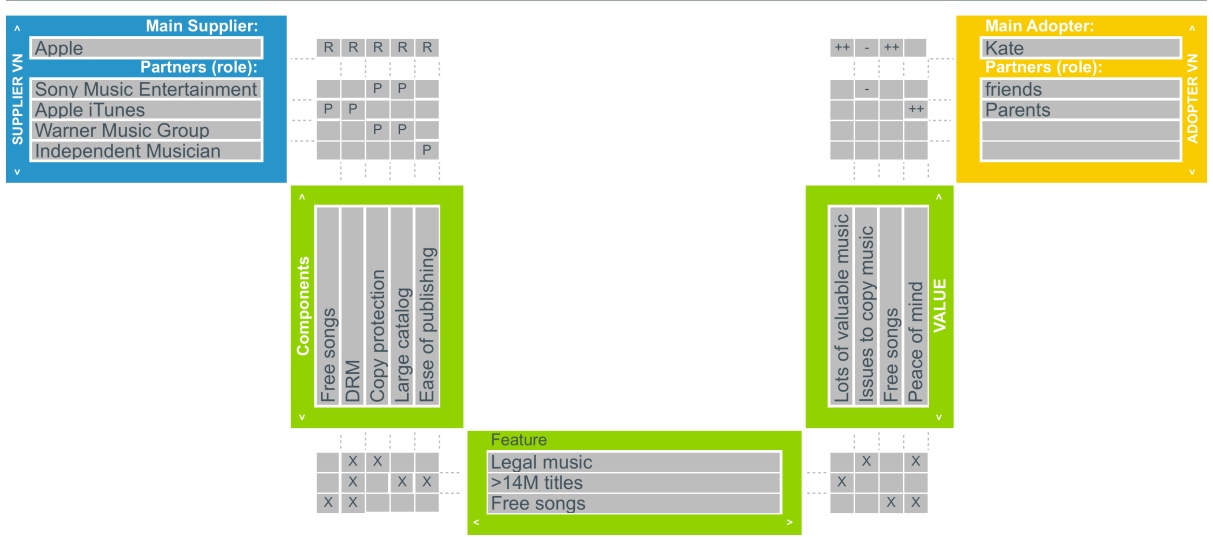

Figure 4 Value model for value in use

The Service System modeled in Figures 3 and 4 contains an additional player in Kate's relationships, Kate's parents. Kate's parents highly value the legal music offered by iTunes since it gives them peace of mind by striking a bargain with Kate that a few iTunes card 
every now and then and the free songs offered by iTunes will be enough to dissuade her from downloading music from the internet.

We therefore see that Kate and her parents have different appreciative systems. While Kate sees and values mostly her relationships with songs and friends, her parents see and value their relationships with society as exemplified by their adherence for legal music. Hence they see different features of the iPod and value them differently. For Apple as a service provider

\section{Related Work}

Value modeling has been introduced long ago in the fields of Requirements Engineering, Information Systems, and Service Science see for example [5, 6, 9]. E3Service [5] is a method for semi-automatically reasoning about matching service offerings with customer needs. In order to make this semi-automatic reasoning possible, e3Service assumes that the customer and supplier share the same ontology, that the customer specifies her needs in the same vocabulary as the supplier specifies its offering. As we have shown, this is a strong assumption when different appreciative systems are connected. Osterwalder and Pigneur [9] define value as a benefit for a customer and describe several kinds of value propositions: Value creation, value appropriation, value consumption, value renewal and value transfer.

Val IT [7] is a governance framework designed to assist organizations to improve the success rate of their IT investments. Val IT seeks to bring value to the organization by balancing the expectations of stakeholders and the resources needed for meeting these expectations. Most notably, Val IT defines that Value is in the eye of the beholder. Val IT focuses mainly on the delivery of projects that bring value to the organization. Business value is also a central pre-occupation in other business frameworks such as ITIL, COBIT, PRINCE2, PMBoK and BABoK.

Soft Systems Methodology (SSM) [3] is a well-known stream of research that is a direct descendant of Vickers's ideas. Checkland [4] proposes a simplified model of Vickers's appreciative system. SSM uses rich pictures as visual models.

Weick [20] proposes an organizational theory called sensemaking that has sometimes been compared and opposed to Vickers's apprecia- 
tive system. Even though Weick talks less explicitly about the valuation process, sensemaking can provide a useful perspective on this process.

\section{Conclusions and Future Work}

In this paper we have shown how Vickers's appreciative system can be used as a theoretical background for modeling and analyzing service systems and their co-creation of value. We have shown how the customers appreciate different aspects of an iPod and the service that Apple has built around it depending on the relationships they manage in their quest for survival in a network of actors.

In the quest for a fuller understanding of service systems, much work is needed still.

Vickers's work, for example, is much richer than what we can capture in this paper. For example, Vickers notes that the norms that serve individuals and organizations in their appreciation remain very often tacit and therefore difficult or impossible to express. It is necessary to create methods to elicit these norms. Requirements Engineering elicitation methods can be used for this purpose. Vickers makes another important point, these norms are not only tacit, they are mutually inconsistent, leading to the need to make multi-valued choices. We will need to extend our models to take these aspects into account.

Independently of Vickers's framework, we need to explicitly link the value in exchange and value in use models to show their interdependence and extend our models to show the flow of value from customer to supplier.

\section{References}

1 Barile, S., Polese, F.: Smart Service Systems and Viable Service Systems: Applying Systems Theory to Service Science. Service Science 2 (1/2), Services Science Global (2010)

2 Barile, S., Spohrer, J., Polese, F.: System Thinking for Service Research Advances. Service Science $2(1 / 2)$, Services Science Global (2010)

3 Checkland, P. and Scholes, J.: Soft System Methodology in action. Wiley, Chichester UK (1990)

4 Checkland, P: Webs of significance: the work of Geoffrey Vickers. Systems Research and Behavioral Science, 22:4, Wiley (2005) 
5 de Kinderen, S., Gordijn, J.: e3 service: A model-based approach for generating needsdriven e-service bundles in a networked enterprise. Proc. 16th European Conference on Information Systems (2008)

6 Gordijn, J., Akkermans, J.M.: Value-based requirements engineering: exploring innovative e-commerce ideas. Requirement Engineering, 8:2, 114-134, Springer (2003)

7 IT Governance Institute: Enterprise Value: Governance of IT Investments, The Val IT Framework 2.0. ITGI, Rolling Meadows, IL (2008)

8 Maglio, P.P., Vargo, S.L., Caswell, N., Spohrer, J., The service system is the basic abstraction of service science. Information Systems and E-Business Management 7:4, 395406 (2009)

9 Osterwalder, A., Pigneur, Y.: Modselling Value Propositions in E-Business. Proc. Second International Conference on Entertainment Computing (ICEC) Pittsburgh, PA (2003)

10 Osterwalder, A., Pigneur, Y.: Business Model Generation. 2010

11 Regev, G., Wegmann, A.: Where do Goals Come From: the Underlying Principles of Goal-Oriented Requirements Engineering. Proc. 13th IEEE International Requirements Engineering Conference (RE'05), Paris (2005)

12 Regev, G. Gause, D.C., Wegmann, A.: Creativity and the Age-Old Resistance to Change Problem in RE. Proc. 14th IEEE International Requirements Engineering Conference (RE'06), Minneapolis, MN (2006).

13 Regev, G., Hayard, O., Gause, D.C. Wegmann, A.: Toward a Service Management Quality Model. Proc.15th International Working Conference on Requirements Engineering: Foundation for Software Quality (REFSQ'09), Amsterdam, The Netherlands (2009)

14 Vargo, S.L., Maglio, P.P., Akaka, M.A.: On value and value co-creation: A service systems and service logic perspective. European Management Journal 26:3, 145-152, (2008)

15 Vickers, Sir G.: Value Systems and Social Process. Tavistock, London (1968)

16 Vickers, Sir G.: Policymaking, Communication, and Social Learning. Transaction Books. New Brunswick NJ (1987)

17 von Bertalanffy, L.: General System Theory, New York, George Braziller (1968)

18 Wegmann, A.: On the Systemic Enterprise Architecture Methodology (SEAM). International Conference on Enterprise Information Systems (ICEIS), Angers, France (2003)

19 Wegmann, A., Regev, G., Rychkova, I., Julia, P., Perroud, O.: Early Requirements and Business-IT Alignment with SEAM for Business, 15th IEEE International Requirements Engineering Conference, New Delhi, India (2007)

20 Weick, K. E.: The Social Psychology of Organizing, second edition. McGraw-Hill (1979)

21 Weinberg, G. M.: An Introduction to General Systems Thinking. Wiley \& Sons. New York (1975)

22 Weinberg, G.M., Weinberg, D.: General Principles of Systems Design. Dorset House, New York (1988) 